\title{
THE INVESTIGATION OF UNIVERSITY STUDENTS' KNOWLEDGE ON NUTRITION AND EATING HABITS
}

Ertuğrul Koçak ${ }^{1}$, Atakan Muhammet Parlak ${ }^{1}$, Orkun Salih Kızılkaya ${ }^{1}$, Burak Bardakçı ${ }^{1}$, Musa Eralp Kılıç ${ }^{1}$, Sevgi Eskiocak $^{2}$

${ }^{1}$ Trakya University School of Medicine, Edirne, TURKEY

${ }^{2}$ Department of Biochemistry, Trakya University School of Medicine, Edirne, TURKEY

\section{ABSTRACT}

Aims: The aim of this study is to analyze Trakya University School of Medicine students' knowledge on nutrition and their eating habits. In addition, it is aimed to determine whether there is a relation between knowledge and nutrition habits and whether medical education is enough to learn the correct information.

Methods: The study conducted in May 2018 was carried out by questionnaires given to 681 students, which were composed of 240 first graders, 98 second graders, 78 third graders, 143 fourth graders, and 110 fifth graders. Chi-square method was used to determine the relation between the class and the gender.

Results: Out of all students $30.4 \%$ of them thought that it is harmful to eat fish and yogurt together. $80.3 \%$ of them had the idea that consuming calcium in their diet does not increase iron absorption. $66.9 \%$ of the participants declared that they drink tea without sugar.

Conclusion: It was determined that the students do not apply the information they know correctly to their daily lives. In some questions, it was observed that the students' knowledge about nutrition is insufficient. In order to correct the eating habits and to create public awareness of nutrition, courses about nutrition should be included in the curriculum of medical students.

Keywords: Eating habit, student, survey

\section{INTRODUCTION}

Nutrition is essential for every living organism to survive. Gender, age and body mass index are the factors that should be considered for a proper diet. In addition, healthy foods are necessary for a better nutrition. It is known that many diseases, growth and development disorders occur as a result of an improper $\operatorname{diet}(1)$.

Proper nutrition should be determined by taking into consideration the economic and socio-cultural status of the person as well as the nutritional value of the food. The conditions in which the person is facing may not be suitable for proper and adequate nutrition. In this case, the person needs to consume the most economical and achievable foods with adequate nutritional values (2).
Misleading done by the firms to sell their own products, the absence of the courses about proper nutrition in the curriculums of many universities, and the economic situation of university students can be the reasons for poor nutrition.

In this study, it is aimed to analyze Trakya University School of Medicine students' knowledge on nutrition and their eating habits. It is also aimed to determine the effect of the absence of courses about proper nutrition in the curriculum of medical students, on their eating habits. 


\section{MATERIAL AND METHODS}

This study has been approved by Scientific Research Ethics Committee of Trakya University School of Medicine. The research was conducted in May 2018 and it is a descriptive cross-sectional study. The participants of the study are 1st, 2nd, 3rd, 4th, and 5th grade students in Trakya University School of Medicine. The study was conducted by questionnaires consisting of 8 questions which were given by hand to the participants (Table 1). The participants were selected on a voluntary basis and the necessary information was written on the questionnaire. It was planned to be conducted on 1257 students however the number of students participating in the survey was 681 . Of these students, 240 of them were first graders, 98 were second graders, 78 were 3 rd graders, 143 were 4 th graders and 110 were 5 th graders. 12 students left the class section blank in the questionnaire and those students were not included in the study.

In the questionnaire distributed to the participants, the classes they are in was asked in order to determine whether the knowledge on nutrition was related to the level of received education. Participants were asked to indicate their gender in order to determine the role of gender in daily nutrition. The presence of chronic diseases was also asked to determine whether participants' habits were related to the diseases or not. Some of the questions were about knowledge or habits whereas some of them were questioned both of them in order to determine whether the knowledge is applied to their habits.

Question 1, 2, 3, 7A and 8A were asked to analyze the knowledge of the students whereas question $4,5,6$, $7 \mathrm{~B}$ and $8 \mathrm{~B}$ were asked to analyze the habits of the participants.

As WHO indicates, $24.8 \%$ of the world population has iron deficiency anemia (3). Therefore, question 3 was asked to determine the knowledge of medical students about the foods which should be consumed in order to decrease the prevalence of this disease.

Since salt consumption is one of the factors which plays a role in hypertension, question 4 was asked to the students in order to analyze the prevalence of salt consumption (4).

The relationship between sugary drinks and body mass index is directly proportional (5). In addition,
Turkey has the highest tea consumption per person in the world with $2.5 \mathrm{~kg}$ per capita (6). With this information in mind, in order to examine the sugar consumption with tea, question 5 was asked to the students where the tea is consumed the most.

Turkey has also the highest bread consumption in the world with $199.6 \mathrm{~kg}$ per capita in a year (7). Not only the amount of bread consumed but also, the type of the bread is important for health. Question 7A and $7 \mathrm{~B}$ were included in the questionnaire in order to determine both the knowledge and habits of the students about bread consumption.

It has been suggested that coronary artery diseases are more common in men who do not have breakfast (8). Thus, questions $8 \mathrm{a}$ and $8 \mathrm{~b}$ were asked to determine whether the students studying at Trakya University School of Medicine have breakfast and the right information about the importance of breakfast.

Table 1: The questionnaire.

\begin{tabular}{|l|}
\hline 1- Is it harmful to eat fish and yoghurt together? \\
Yes, it is. \\
No, it is not. \\
\hline 2- What is the effect of eating yoghurt besides iron-containing foods on iron absorption? \\
Increases \\
No effect \\
Decreases \\
\hline 3- Which of the following contains more iron element? \\
Meatballs \\
Milk \\
Molasses \\
Spinach \\
Fruits \\
\hline 4- Which describes your salt consumption? \\
I do not add salt to my meals. \\
I add it according to the taste of the meal. \\
I add it without tasting the meal. \\
\hline 5- How many sugar do you add to a glass of tea? \\
None \\
1 or 2 \\
3 or more \\
\hline 6- Which of the following describes your sweets consumption? \\
None \\
1-2 times a week \\
3-5 times a week \\
More than 5 times a week \\
\hline 7- A) Which type of the bread is healthier than the others? \\
White bread \\
Whole wheat bread \\
Bran bread \\
Multigrain bread \\
Other \\
B) Which type of the bread you consume the most? \\
White bread \\
Whole wheat bread \\
Bran bread \\
Multigrain bread \\
Other \\
\hline 8- A) Which meal is more important during the day? \\
Breakfast \\
Lunch \\
Dinner \\
B) Which meal do you care more? \\
Breakfast \\
Lunch \\
Dinner \\
\hline
\end{tabular}


The data were analyzed using Chi-square test on IBM SPSS Software 20.0 to compare the categorical data. Numbers and percentages were used as descriptive statistics to evaluate the given answers.

\section{RESULTS}

Demographic features of the students participated in the study are given in Table 2.

Table 2: Demographic features of the students.

\begin{tabular}{|l|l|l|}
\hline & Number (n) & Percentage (\%) \\
\hline Gender & \multicolumn{2}{|c|}{} \\
\hline Male & 273 & 41.4 \\
\hline Female & 388 & 58.6 \\
\hline Classes & \multicolumn{2}{|l|}{} \\
\hline 1 & 240 & 35.9 \\
\hline 2 & 98 & 14.6 \\
\hline 3 & 78 & 11.7 \\
\hline 4 & 143 & 21.4 \\
\hline 5 & 110 & 16.4 \\
\hline
\end{tabular}

For the first question ('Is it harmful to eat fish and yogurt together?'), there were $472(69.6 \%)$ students who said 'no, it is not' while 206 (30.4\%) students said 'yes, it is'. The distribution of the answers according to the classes is given in Figure 1. The distribution of answers among classes was statistically significant $(\mathrm{p}<0.001)$. The distribution of the answers according to gender is given in Figure 2. The comparision of the answers among the gender groups was not statistically significant $(\mathrm{p}>0.05)$.

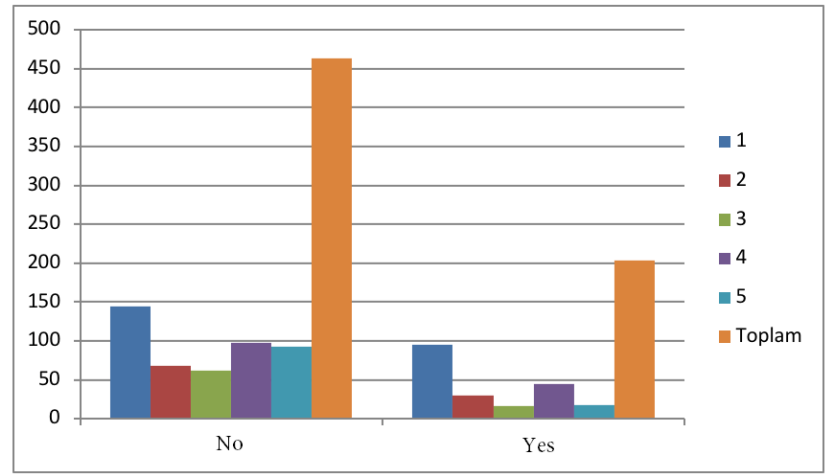

Figure 1: The distribution of the answers to the first question according to the classes.

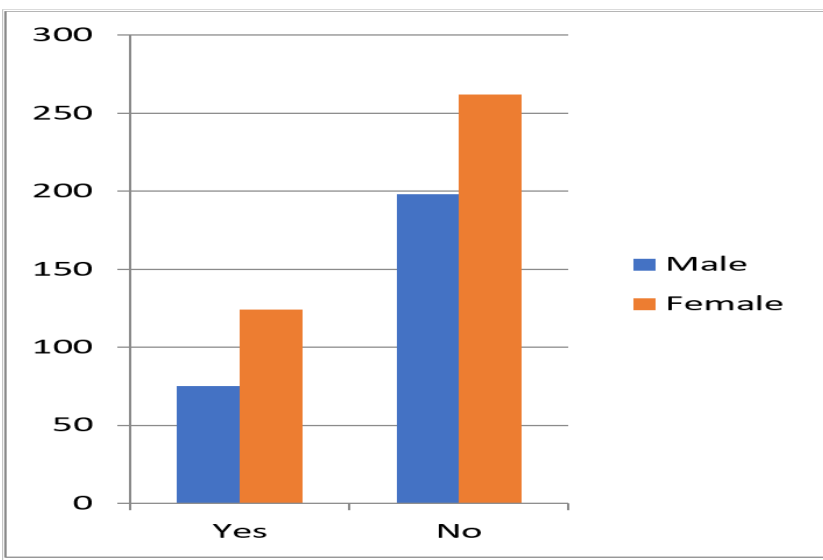

Figure 2: The distribution of the answers to the first question according to gender.

When the effect of calcium intake to iron absorption was asked in question 2 ('What is the effect of eating yogurt besides iron-containing foods on iron absorption?'), 133 (19.7\%) students chose 'increases', 157 (23.2\%) of them chose 'no effect' and 386 (57.1\%) students chose 'decreases'. The distribution of the answers according to gender is given in Figure 3. There was a statistically significant difference among the gender groups regarding the given answers $(\mathrm{p}<0.01)$. The distribution of answers according to the classes is given in Figure 4.

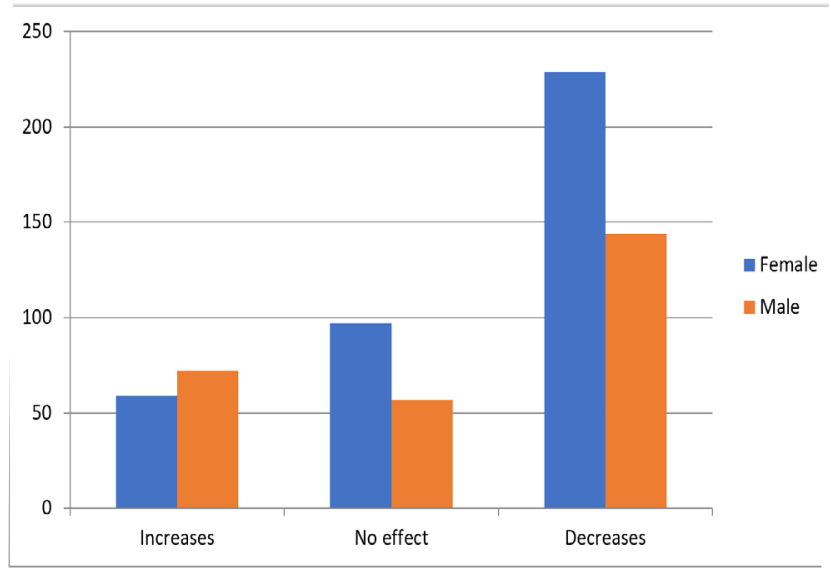

Figure 3: The distribution of the answers to question 2 according to gender. 


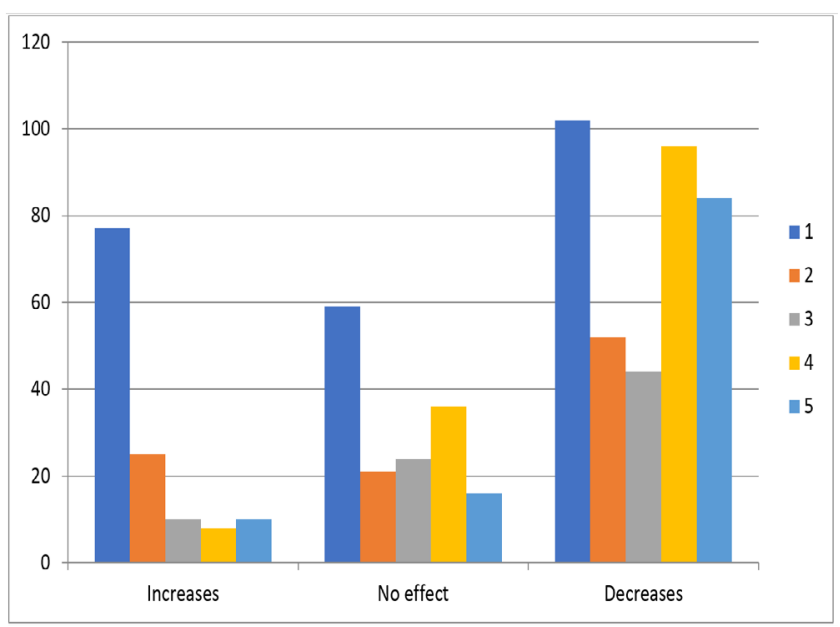

Figure 4: The distribution of the answers to question 2 according to classes.

For the third question ('Which of the following contains more iron element?'), 241 (40.1\%) students chose meatballs, 17 (2.5\%) students chose milk, 207 (30.6\%) students chose molasses, 176 (26\%) students chose spinach and $5(0.7 \%)$ students chose fruits. The distribution of the answers according to genders are as follows: 166 (42.9\%) female students and 97 (35.9\%) male students chose meatballs, 7 (1.8\%) female students and $9(3.3 \%)$ male students chose milk, 128 (33.1\%) female students and $74(27.4 \%)$ male students chose molasses, $83(21.4 \%)$ female students and $89(33 \%)$ chose spinach, $3(0.8 \%)$ female students and $1(0.4 \%)$ male students chose fruits.

The distribution of the answers according to the classes is given in Figure 5.

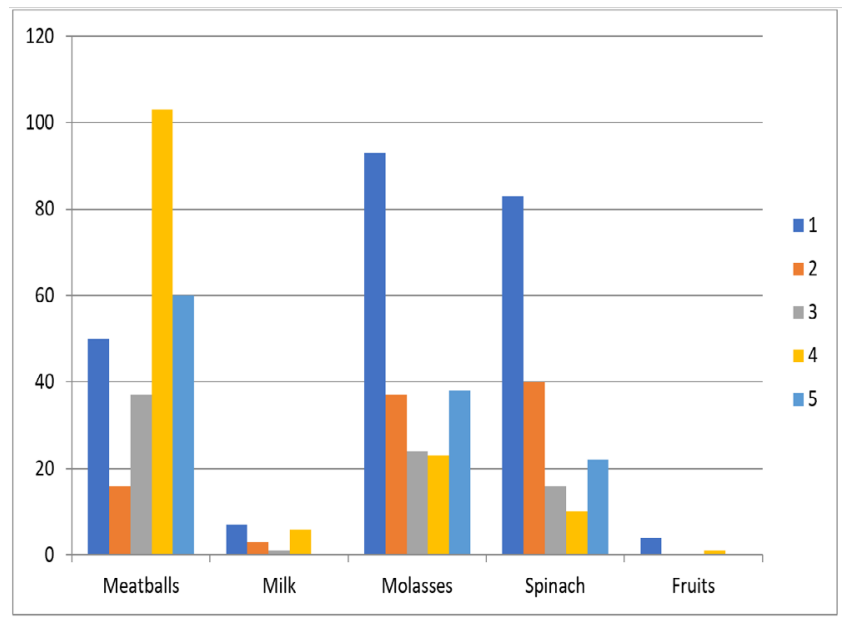

Figure 5: The distribution of the answers to question 3 according to classes.
In the questionnaire, the participants were asked whether salt, which is one of the main causes of cardiovascular diseases, was used as a habit in their daily lives. 166 (24.4\%) of the participants stated that they have never used it. 464 (68.3\%) participants said that they add it according to the taste of the meal and 49 (7.1\%) participants stated that they add it without tasting the meal.

Four-hundred-fifty-three (66.9\%) participants drink tea without sugar, whereas $196(28.8 \%)$ students use 1 or 2 cubes of sugar. 29 (4.2\%) participants drink tea with 3 or more cubes of sugar.

When sweet consumption was asked, the answers were as follows: $31(4.6 \%)$ students do not eat any sweets, $304(44.7 \%)$ students eat sweets 1 or 2 times in a week, $215(31.6 \%)$ students eat sweets 3 to 5 times in a week, and $131(19.2 \%)$ students eat sweets more than 5 times a week.

In order to analyze the effect of knowledge on habits, the answers to the questions about 'Bread Consumption' and 'Meal Preference' are given in Figure $6 a, 6 b, 9 a, 9 b$ respectively. The distribution of the answers according to gender is given in Figure 7. There was no statistically significant difference found between the answers when the gender groups were compared $(\mathrm{p}>0.05)$. The distribution of the answers according to the classes is given in Figure 8 and 10.

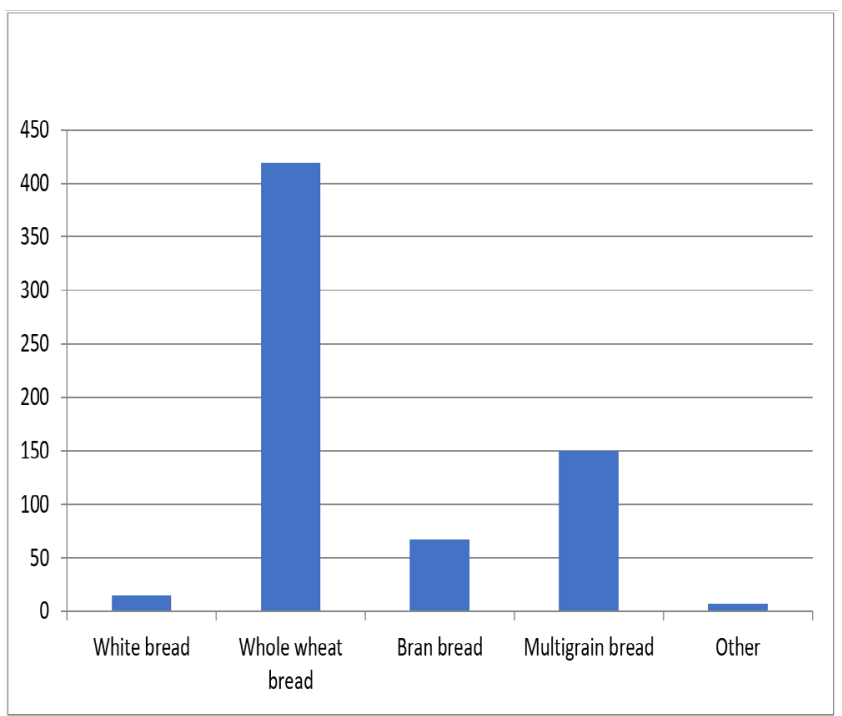

Figure 6a: The distribution of the answers given to the question $7 a$ (Which type of the bread is healthier than the others?). 


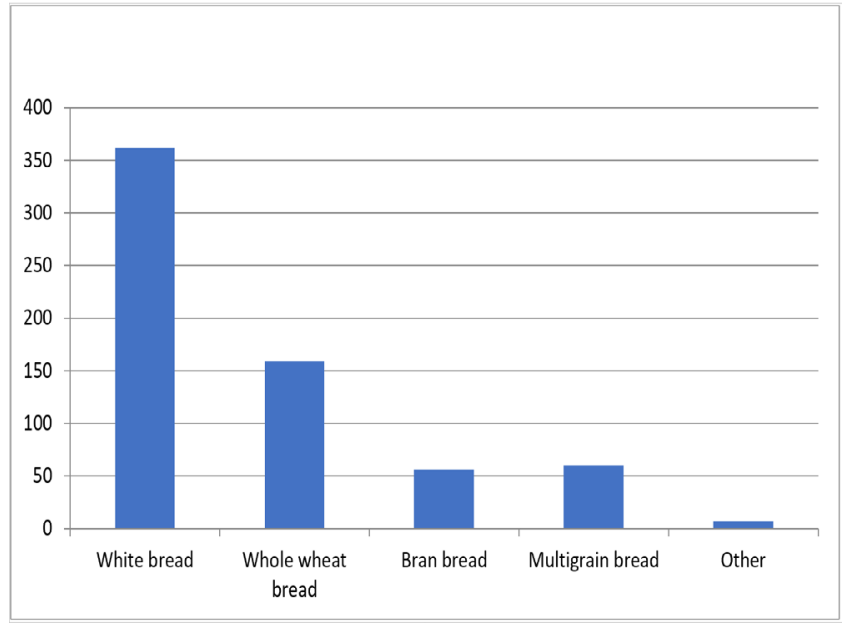

Figure 6b: The distribution of the answers given to the question $7 b$ (Which type of the bread you consume the most?).

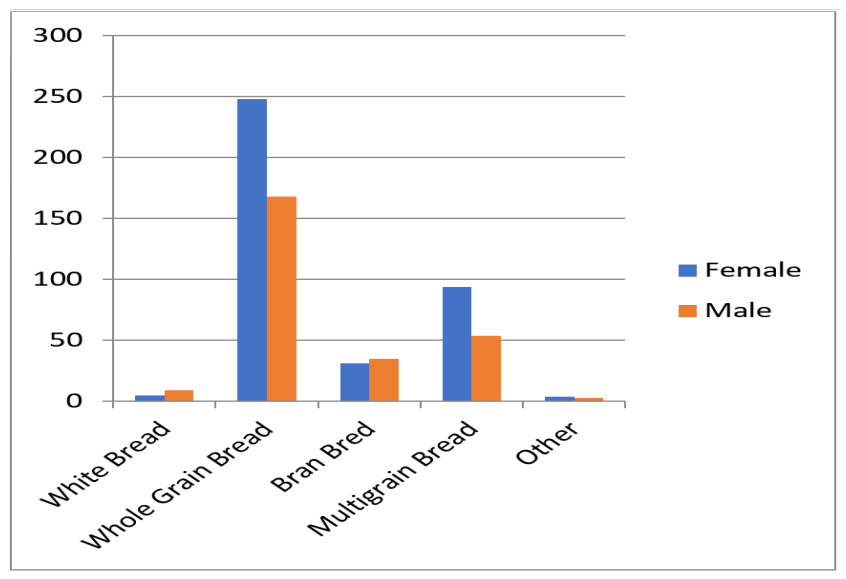

Figure 7: The distribution of the answers to question $7 A$ according to gender.

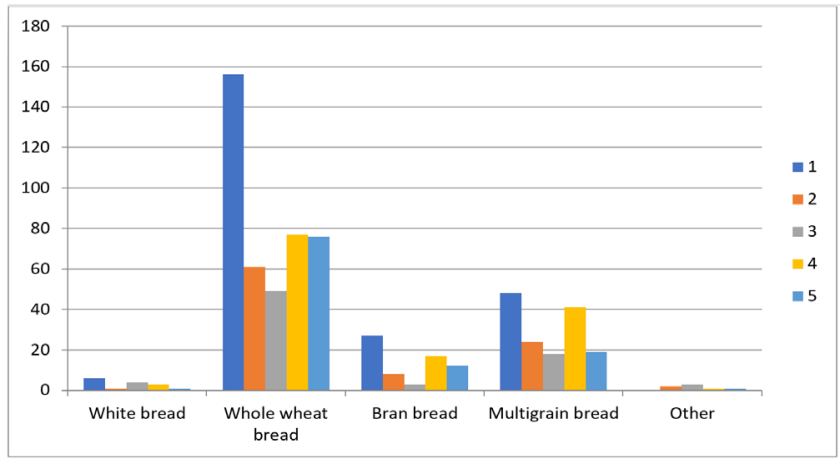

Figure 8: The distribution of the answers to question $7 B$ according to the classes.

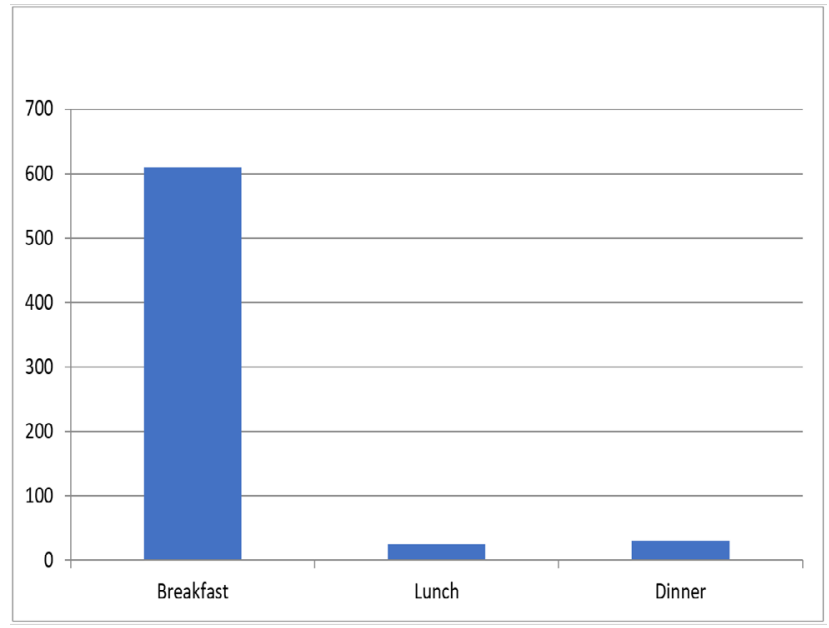

Figure 9a: The answers to question $8 A$.

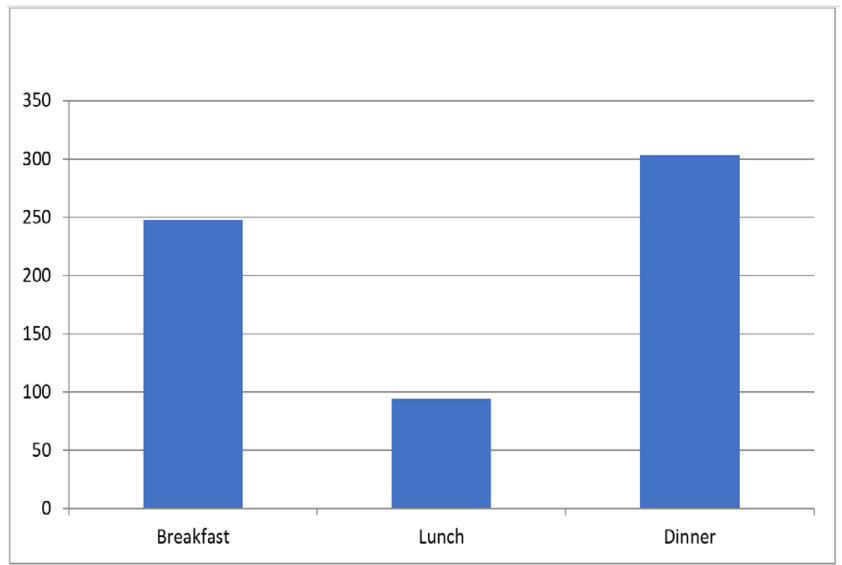

Figure 9b: The answers to question $8 B$.

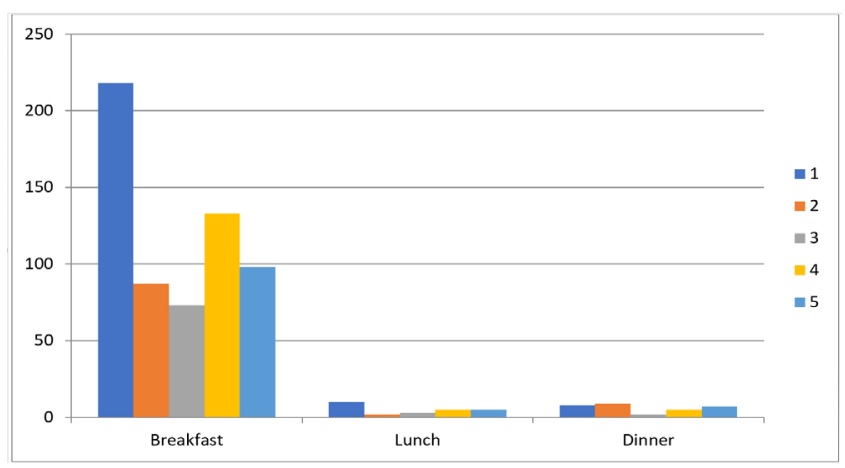

Figure 10: The distribution of the answers to question $8 A$ according to classes. 


\section{DISCUSSION}

Today, there is a considerable number of people who have health problems due to insufficient and unconscious nutrition. Malnutrition is among the causes of many diseases such as cardiovascular diseases, obesity, and cancer. The treatment for these diseases is taking a sufficient amount of nutrients that the body needs (2).

Proper food preferences have great importance in preventing such diseases (9). One of doctors' primary tasks is to protect public health and to guide the public in the subject of nutrition. For this reason, it will be appropriate for doctors to take nutrition education as well as medical education. For example, Çalıştır et al (1) conducted a research on 792 students in Muğla University Central Campus. The top score was 25 and according to the results of the study, the ratio of the students whose score was between 18 and 20 was just $21.09 \%$ (1). Therefore, with this study, it is aimed to determine whether the education in Trakya University School of Medicine is enough to learn the proper and sufficient nutrition and to adapt this knowledge to their lives.

For the question about eating of fish and yogurt together, $69.6 \%$ of the students answered that it is not harmful. Therefore, it can be said that this common misconception is not widespread among medical students. However, every 3 students out of 10 students think that eating both fish and yogurt together is harmful. Based on this result, it can be said that medical education reduces misinformation.

It is known that calcium taken at pharmacological level reduces the absorption of iron by competing with iron in DMT-1 (Divalent metal transporter-1) mediated transport, but it has been proved that there is no negative effect of the amount of calcium that can be taken with nutrients in iron absorption (8). However, $57.1 \%$ of the participants thought that consuming meat and yogurt would reduce iron absorption. Only $23.2 \%$ of the participants thought that the amount of calcium taken with nutrients will not change the absorption of iron.

In question 3, $40.1 \%$ of the students gave the right answer by saying that meatballs contain more iron element than the other foods. However, there was no significant difference between the given answers among the classes $(p=6,98)$. Therefore, it could be said that medical education may not have a contribution in that subject.

In Turkey, $14.3 \%$ of men and $23.4 \%$ of women have hypertension (4). It is known that salt intake increases blood pressure and causes hypertension. According to the results of the survey, it is seen that the 'taste of food' is the criteria for salt consumption.

As it is mentioned before, the consumption of sugary drinks and body mass index are related (5). Additionally, Turkey has the highest tea consumption per capita (6).

In our study, $66.9 \%$ of the students which is the majority of the students do not add sugar to their tea. The last two questions in the survey were composed of two sub-questions which were given as $\mathrm{A}$ and $\mathrm{B}$. The aim of these two questions was to reveal whether the students' knowledge is reflected in the habits. $97.8 \%$ of the students thought that the consumption of white bread is not healthy whereas $56.4 \%$ of them consume white bread in their daily life. The reason behind white bread being so widespread may be the economic situation of the students and the difficulty of accessing other bread varieties can be shown. The contents of whole wheat bread are defined as complex carbohydrates. Digestion time of complex carbohydrates is longer than simple carbohydrates. They do not increase blood sugar quickly and do not over-stimulate insulin release from the pancreas. Since they do not cause hyperinsulinemia, blood sugar does not drop rapidly after meals and do not cause to eat more. The proportion of women who think that it is beneficial to consume whole-wheat bread is higher than men (10).

The second question which the habits of students were investigated, were composed of two sub-questions: 'Which meal is more important during the day?' and 'Which meal do you care more?'. Energy is needed to perform daily activities and $15 \%-20 \%$ of this energy is met by the first meal of the day. Skipping breakfast, which is the first meal of the day, leads to significant health problems. For example, the risk of coronary heart disease has been shown to be $27 \%$ higher in men who do not have breakfast than men who have breakfast (11). $91.6 \%$ of the students think that breakfast is the most important meal, but $38.2 \%$ of them have breakfast as a habit. According to the survey conducted on 357 male students studying at Qassim University Faculty of Health Sciences in Saudi Arabia, $49.9 \%$ of the students stated that they have breakfast every day (12). 
In a survey conducted by Yilmaz et al (2) on 175 students studying in Balıkesir University Bandırma School of Health Nursing and Bandirma Vocational School of Child Development departments, $59.4 \%$ of the research group gives importance to breakfast and $29.7 \%$ of the students do not have breakfast. One of the reasons why students cannot pay attention to breakfast can be that breakfast preparation cannot be done in the dormitory or apart conditions. In this question, as in the previous habit-knowledge question, the rate of women who think that the most important meal is breakfast is more than that of men.

As a conclusion, having a course about proper nutrition in the curriculum of medical schools may have a contribution to increase the rate of right answers in the survey. Medical students who know proper nutrition may influence the public in the future as well. It may lead to a decrease in diseases which were caused by poor nutrition in our country for future generations. Giving courses about nutrition to the public may contribute the knowledge of new generations.

Ethics Committee Approval: This study was approved by Scientific Researches Committee of Trakya University School of Medicine.

Informed Consent: Written informed consent was obtained from the participants of this study.

Conflict of Interest: The authors declared no conflict of interest.

Author contributions: Concept: EK, AMP, OSK, BB, MEK, SE. Design: EK, SE. Supervision: EK, SE. Resources: EK, SE. Materials: EK, AMP, OSK, BB, MEK, SE. Data collection and/or processing: EK, AMP, OSK, BB, MEK, SE. Analysis and/or Interpretation: EK, AMP, OSK, BB, MEK, SE. Literature Search: EK, AMP, OSK, BB, MEK, SE. Writing Manuscript: EK, SE. Critical Review: EK, SE.

Financial disclosure: The authors declared that this study received no financial support.

\section{REFERENCES}

1. Çalıştır B, Dereli F, Eksen M et al. Muğla üniversitesi öğrencilerinin beslenme konusunda bilgi düzeylerinin belirlenmesi. Uluslararası İnsan Bilimleri Dergisi 2005;2(2):1-8.

2. Yılmaz E, Özkan S. Üniversite öğrencilerinin beslenme alışkanlıklarının incelenmesi. Fırat Sağlık Hizmetleri Dergisi 2007;2(6):88-104.
3. Benoist B, McLean E, Egli I et al. Worldwide prevalence of anaemia 1993-2005. WHO Global Database of Anaemia 2008.

4. Onat A, Türkmen S, Karabulut A et al. Türk yetişkinlerde hiperkolesterolemi ve hipertansiyon birlikteliği: sıklığına ve kardiyovasküler riski öngördürmesine ilişkin tek harf çalışma verileri. Türk Kardiyoloji Derneği Arş. 2004;32:533-41.

5. Ludwig D, Gortmarker S. Relation between consumption of sugar-sweetened drinks and childhood obesity: a prospective observational analysis. The Lancet 2001;357(9255):505-8.

6. Euromonitor International. Turkey: Second biggest tea market in the world. DJS Research (serial online) 2005 Apr (cited 2018 Sep 10). Available from: URL:http://marketresearchworld.net/content/view/208/.

7. Largest bread consumption per capita. Guinnes World Records (serial online) 2000 (cited 2018 Sep 10). Available from: URL:http://www.guinnessworldrecords.com/world-records/largest-bread-consumption-per-capita.

8. Nantel G, Tontisirin K. Human Vitamin and Mineral Requirements. FAO/WHO 2001.

9. Barzegari A, Ebrahimi M, Azizi M et al. Study of nutrition knowledge, attitudes and food habits of college students. World Applied Sciences Journal 2011;15(7):1012-7.

10. Eleazu CO. The concept of low glycemic index and glycemic load foods as panacea for type 2 diabetes mellitus; prospects, challenges and solutions. African Health Sciences 2016;16(2):468-79.

11. Spence C. Breakfast: the most important meal of the day?. International Journal of Gastronomy and Food Science 2017;8:1-6.

12. Al-Rethaiaa, Fahmy AE, Al-Shwaiyat NM. Obesity and eating habits among college students in Saudi Arabia: a cross sectional study. Nutr J 2010;9:39. 